\title{
Impact of Retropubic vs. Transobturator Slings for Urinary Incontinence on Myofascial Structures of the Pelvic Floor, Adductor and Abdominal Muscles
}

\author{
Einfluss retropubischer vs. transobturatorischer Bandeinlage bei Harninkontinenz auf myofasziale Strukturen \\ der Beckenboden-, Adduktoren- und Abdominalmuskulatur
}

Authors

Affiliations
K. Beilecke ${ }^{1}$, S. Soeder ${ }^{2}$, E. Hufenbach ${ }^{3}$, R. Tunn ${ }^{1}$

DBBZ, Klinik für Urogynäkologie, St. Hedwig Krankenhaus, Berlin

2 Praxis für Physiotherapie, DBBZ, Berlin

${ }^{3}$ Frauenklinik, Vivantes-Klinikum Hellersdorf, Berlin

\section{Key words}

urinary incontinence

- retropubic sling

- transobturator sling

- postoperative pain

pelvic floor function

\section{Schlüsselwörter}

- Harninkontinenz

- retropubisches Band

- transobturatorisches Band

- postoperative Schmerzen

- Beckenbodenfunktion

Deutschsprachige Zusatzinformationen online abrufbar unter: www.thieme-connect.de/ ejournals/toc/gebfra received 8.6.2013

revised 16.10 .2013

accepted 24.11.2013

\section{Bibliography}

DOI http://dx.doi.org/

10.1055/s-0033-1360222

Geburtsh Frauenheilk 2014; 74:

69-74 @ Georg Thieme

Verlag KG Stuttgart · New York ISSN 0016-5751

\section{Correspondence}

\section{Dr. Kathrin Beilecke}

St. Hedwig Krankenhaus

DBBZ, Klinik für Urogynäkologie Große Hamburger Straße 5-11

10115 Berlin

k.beilecke@alexius.de

\section{Abstract \\ $\nabla$}

Suburethral tension-free slings (tapes or bands) are an essential component in the operative treatment of urinary incontinence. In the present contribution the influence of the type of suburethral sling (retropubic vs. transobturator) on the myofascial structures of the abdominal, adductor and pelvic floor muscles is examined. For this purpose, 70 patients were prospectively observed clinically and physiotherapeutically. Significant differences were seen in the improvement of the pelvic floor musculature (strength, endurance, speed) after placement of a suburethral sling, irrespective of whether it was of the retropubic or the transobturator type. Thus, after surgical treatment patients should be encouraged to undertake further pelvic floor exercising or this should be prescribed for them. There were no significant changes in the abdominal and adductor muscles but there were slight increases with regard to pain level, pain on palpation, and trigger points after placement of both types of sling; thus this is not a criterion in the decision as to which type of sling to use.

\section{Introduction}

Suburethral tension-free slings (tapes or bands) have been an essential component of the surgical treatment for stress urinary incontinence for some years. Nowadays we distinguish between three types of suburethral sling: retropubic, transobturator and intraobturator [1-3]. The success rates of all slings are high with low incidences of complications [3-8]. Even so, specific "side effects" are assigned to the various techniques.

Typical "side effects" of retropubic slings are intraoperative bladder perforation and postoperative retropubic haematomas which, since intro-

\section{Zusammenfassung \\ $\nabla$}

Suburethrale spannungsfreie Bänder sind fester Bestandteil der operativen Therapie der Harninkontinenz. In der vorliegenden Arbeit wurde der Einfluss der Art des suburethralen Bandes (retropubisch vs. transobturatorisch) auf die myofaszialen Strukturen der Abdominal-, Adduktoren- und Beckenbodenmuskulatur untersucht. Dazu wurden 70 Patientinnen prospektiv klinisch und physiotherapeutisch beobachtet. Signifikante Unterschiede zeigten sich in der Verbesserung der Beckenbodenmuskulatur (Kraft, Ausdauer, Schnelligkeit) nach der Einlage eines suburethralen Bandes, unabhängig ob retropubisches oder transobturatorisches Band. Daher sollten die Patientinnen nach einer operativen Therapie zu weiterem Beckenbodentraining ermuntert bzw. dieses verordnet werden. In der Abdominal- und Adduktorenmuskulatur ergaben sich keine signifikanten Veränderungen, aber eine leichte Zunahme in Bezug auf Schmerzhaftigkeit, Druckdolenzen und Triggerpunkte nach der Einlage beider Bänder, sodass das kein Kriterium in der Entscheidung für eine Art des Bandes sein muss.

duction of the transobturator sling, practically no longer occur $[6,7]$. This had induced a certain euphoria with regard to transobturator slings. However, with the wider use of these slings specific problems also became apparent, above all pain in the groin region spreading down to the inner side of the thigh. The haematomas now spread to the region of the adductor muscles. In isolated cases necrotising fasciitis has been described in this region $[9,10]$.

Experience from the daily routine of a pelvic floor centre has shown that the pain that occasionally occurs after placement of a transobturator sling can be attributed to the innervation zones of various different nerves (obturator nerve, femoral 
nerve, genitofemoral nerve). On the other hand there are some cases in which women with retropubic slings also suffer from pain events that neurologically correspond to the innervation zones of the same nerves (femoral, genitofemoral nerves). Since these cases of pain can mostly be effectively treated by physiotherapy, it is assumed that the nerves are less often directly irritated. There is rather a myofascial dysbalance of the affected muscles since in both methods the sling is passed through muscular and fascial structures.

In the transobturator technique the insertions of the adductor muscles are perforated with the needle and the ligament is dissected epifascially. This technique with perforation of the insertions of the abdominal muscles and epifascial shortening of the band is performed in analogy to placement of retropubic slings. If this perforation of the muscle insertions should be the reason for the postoperative pain, then the pain should also arise in the region of the abdominal muscles after placement of retropubic slings. In the available studies it was merely investigated whether the directly affected muscle groups of the adductor and abdominal musculature react with the same pattern on the positioning of a polypropylene sling in their insertions and if the perception of the patients in the differing muscle groups varies. Are the patients perhaps less sensitive in the region of the pelvic floor musculature since this is often restricted in its function due to the strains of life and respective poor posture? And, on the other hand, is the adductor musculature more frequently "involved" so that pain here is more readily perceived?

A further question is to what extent the varying types of sling or, respectively, the restoration of continence have an impact on the pelvic floor muscles (strength, endurance, speed).

\section{Methods}

$\nabla$

In the course of a clinical study from January 2007 through to March 2008, patients of the German Pelvic Floor Centre, St. Hedwig Hospital Berlin, Department of Urogynaecology were prospectively accompanied.

\section{Inclusion criteria and selection of patients}

All patients had an indication for surgical treatment of urometrically confirmed stress urinary incontinence and a previous failed conservative treatment (pelvic floor training and/or drug therapy). The patients were informed about the observational trial and gave their consent in the knowledge that this would have no influence on therapeutic decisions. The motivation for participation was the pre- and postoperative physiotherapeutic clarification and monitoring. The selection of patients was based on clinical and urometric criteria with respect to the indication for surgery. Patients with a lateral defect in level III received a transobturator sling and patients with a hypotonic urethra with a lateral defect in level III became a retropubic sling. In order to ensure an optimal management for the patients even under study conditions a randomisation was not undertaken. The degree of distress was recorded pre- and postoperatively by means of a visual analogue scale. Here the value "0" means "no distress" and the value "10" means "unbearable life situation" due to urinary incontinence. All patients were operated upon by a single surgeon with extensive experience in the methods. They received either a retropubic TVT or a transobturator TVT-O from Gynecare (Johnson \& Johnson MEDICAL GmbH), both in the known inside-out tech- nique as described in the original publication $[2,11]$. The postoperative procedures followed a standardised course.

\section{Physiotherapeutic status and postoperative examinations}

In addition, for each patient on the preoperative day the physiotherapeutic status was assessed by a single physiotherapist with experience in the methodology and additional qualifications in manual medicine. The very same examination was repeated six weeks after surgery in the course of the follow-up. The physiotherapeutic status should reflect the extensive functions of the pelvic floor and relationships between diaphragm and muscle chains so that, above all, not only the abdominal, pelvic and femoral myofascial structures but also the mobility of the flexible joints can be assessed. The following examinations, however, appear to be the most important for the initial objectives:

- Digital examination of the pelvic floor muscles in a supine position and while standing. Strength (maximum 5 of 5) [12], endurance (maximum 10 of 10 seconds) and speed (maximum 10 of 10 contractions) were measured according to the Oxford scheme.

- Examinations of pain, pain on palpation and trigger points [13], always on both sides were performed on the external oblique muscle, transverse abdominal muscle and rectal abdominal muscle for the abdominal musculature, on the long and short adductor muscles for the adductor musculature and on the external obturator muscle as a muscle supporting adduction.

At six weeks post-operation not only the physiotherapeutic status but also the degree of suffering were measured using a visual analogue scale, furthermore, a gynaecological examination, perineal ultrasound to determine residual urine, exclusion of haematomas and positional assessment of the sling were carried out.

\section{Exclusion criteria}

Exclusion criteria for this study comprised previous operations for urinary incontinence, previous neurological diseases such as Parkinson's disease, multiple sclerosis, and slipped disc, pregnancy and age less than 18 years.

\section{Statistics}

The statistical analyses were performed with the help of MedCalc. Average values, standard deviations, minimum and maximum values and median values were determined. For specific characteristics percent frequencies were calculated and tested for their significance. Several groups were tested for significance by means of ANOVA. The level for statistical significance was set at $\mathrm{p}<0.05$, that for highly significant at $\mathrm{p}<0.01$.

\section{Results}

$\nabla$

\section{Patient population and quality of life}

Of the 70 operated patients, 33 (47\%) received a retropubic sling and 37 (53\%) a transobturator sling. All patients were seen at the postoperative follow-up examinations. The age distribution (68/ 65 years) and body mass index (26/25) in the two groups (retropubic/transobturator) were comparable. All were operated in the primary situation, they did not have a descent or had not undergone any previous urogynaecological operations.

The quality of life as expressed with a visual analogue scale was significantly improved after surgery in both groups. With regard 


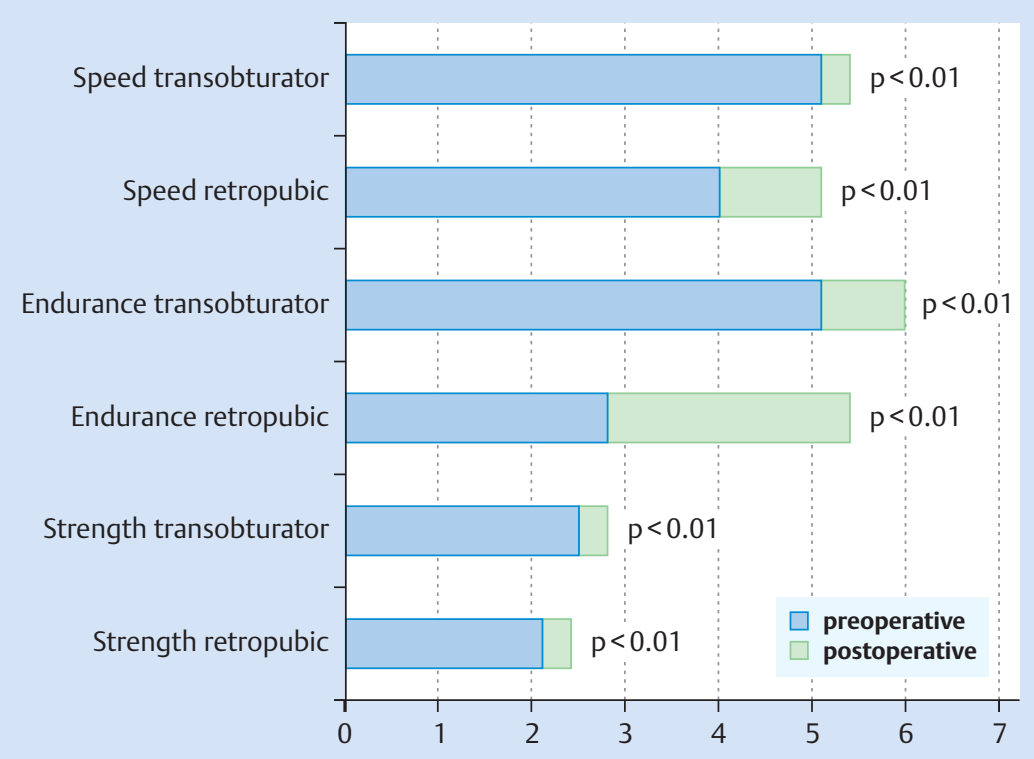

Fig. 1 Pre- and postoperative characteristics of the pelvic floor muscles in patients in the supine position after placement of retropubic and transobturator slings in three categories (postoperative means six weeks after surgery). Speed: 0-10 contractions in $10 \mathrm{~s}$. Endurance in $\mathrm{s}-$ holding the contractions up to $10 \mathrm{~s}$. Strength according to the Oxford scheme [12] 0 to 5 of max. 5.

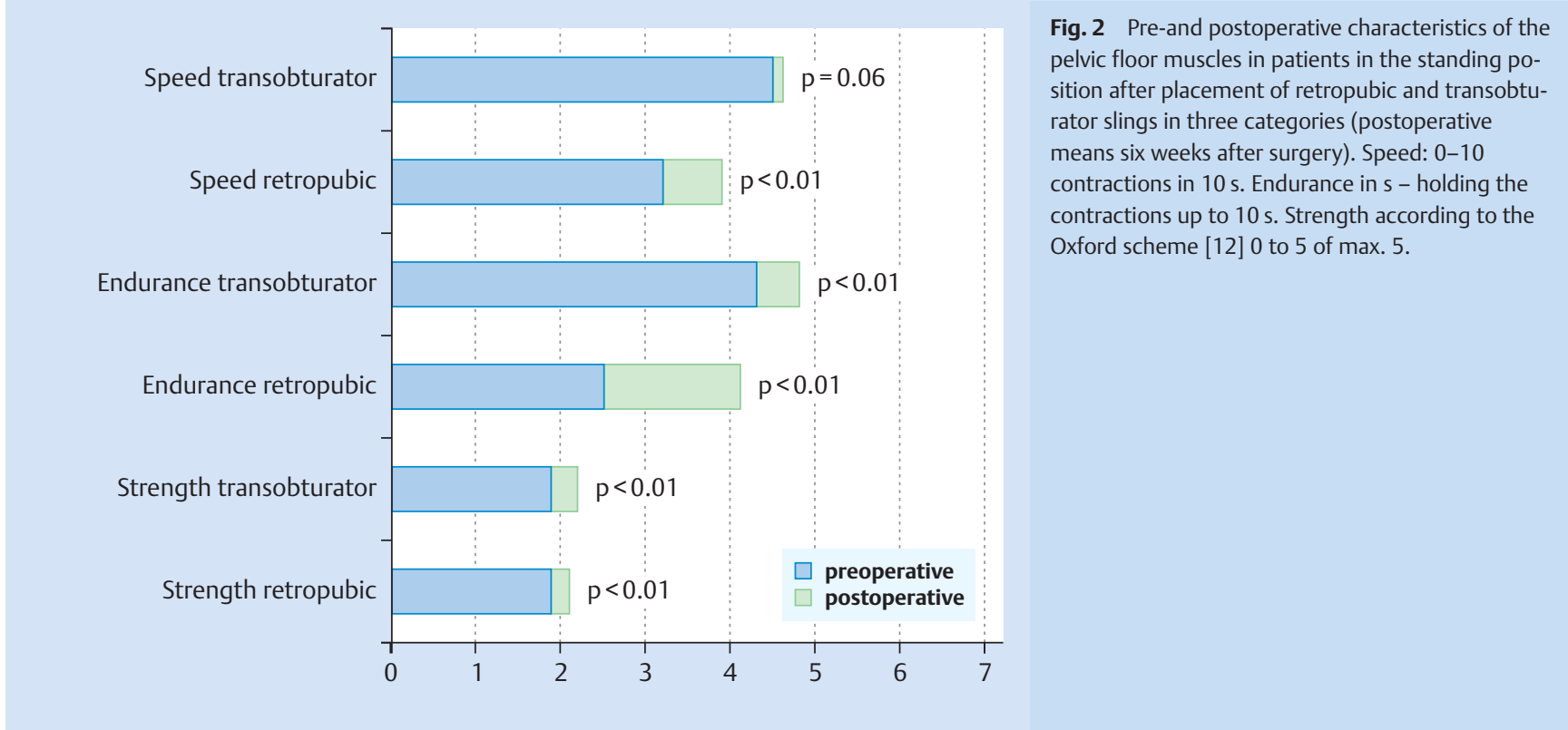

to stress urinary incontinence, the quality of life for those patients who received a retropubic sling improved from preoperative 7.7 to postoperative $3.0(\mathrm{p}<0.01)$, in the group of patients with a transobturator sling from 6.4 to 1.7 ( $p<0.01)$.

Intraoperative complications such as bladder perforations (retropubic sling) and lateral vaginal sulci (transobturator sling) or blood loss in excess of $200 \mathrm{~mL}$ did not occur, the postoperative residual urine amounts did not exceed $50 \mathrm{~mL}$ either at two days or at six weeks after surgery. Postoperative urinary tract infections were not detected. In three patients on the second postoperative day a retropubic haematoma was observed on introitus ultrasound, in one of the patients this was revised on abdominal surgery. All of these patients were members of the group with retropubic slings.
Influence of sling insertion on pelvic floor musculature Evaluation of the physiotherapeutic status in part reached a marked level of significance. The pelvic floor musculature was tested as described above for strength in both supine and standing positions. The results revealed marked improvements in all parameters and in both groups. $\bullet$ Figs. 1 and $\mathbf{2}$ show the results in supine and standing positions, respectively. It can be seen that all parameters have improved significantly, except for speed in standing for those with transobturator slings.

\section{Influence of sling insertion on abdominal} and adductor muscles

In the pre- versus postoperative comparisons of the methods listed below and the muscles investigated for painfulness, pain on palpation and trigger points, a tendency towards a slight increase in pain was found postoperatively, and even unchanged 


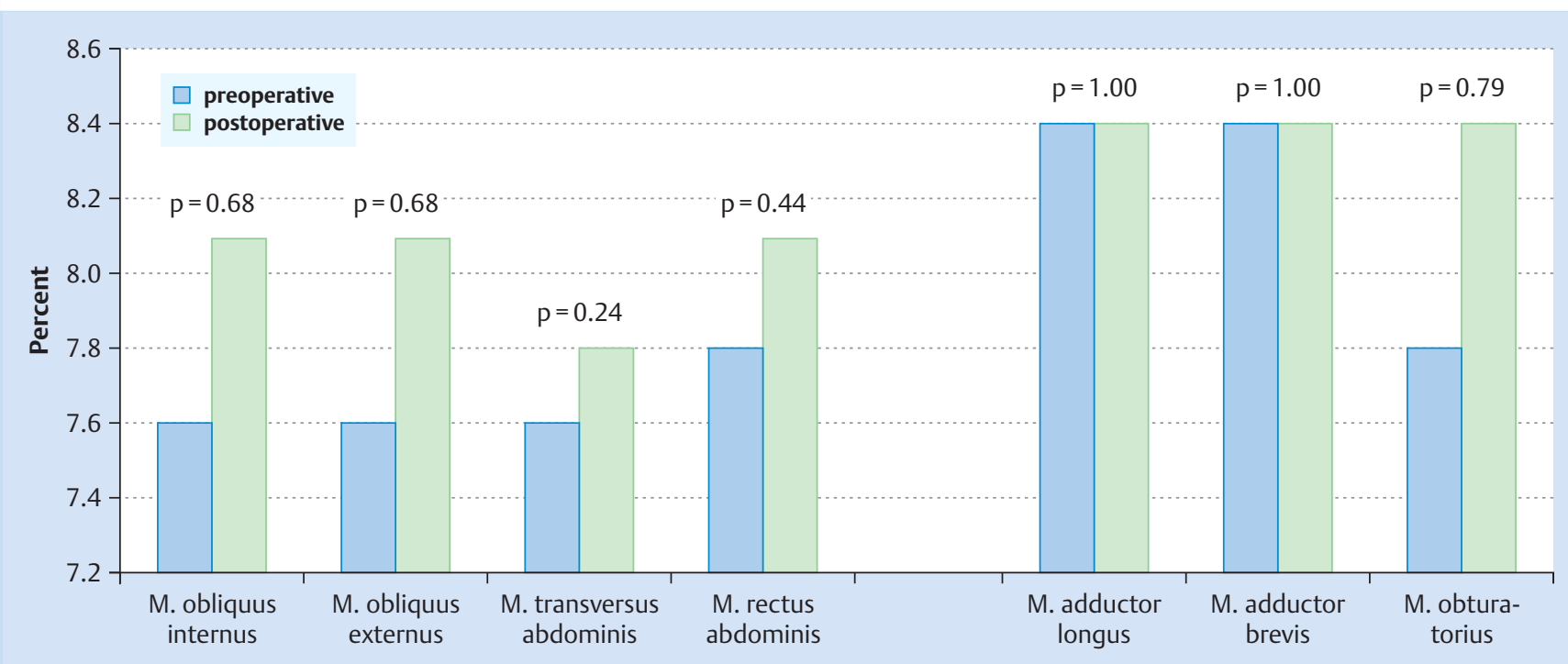

Fig. 3 Pre- and postoperative pain in patients who received a transobturator sling (postoperative means six weeks after surgery).

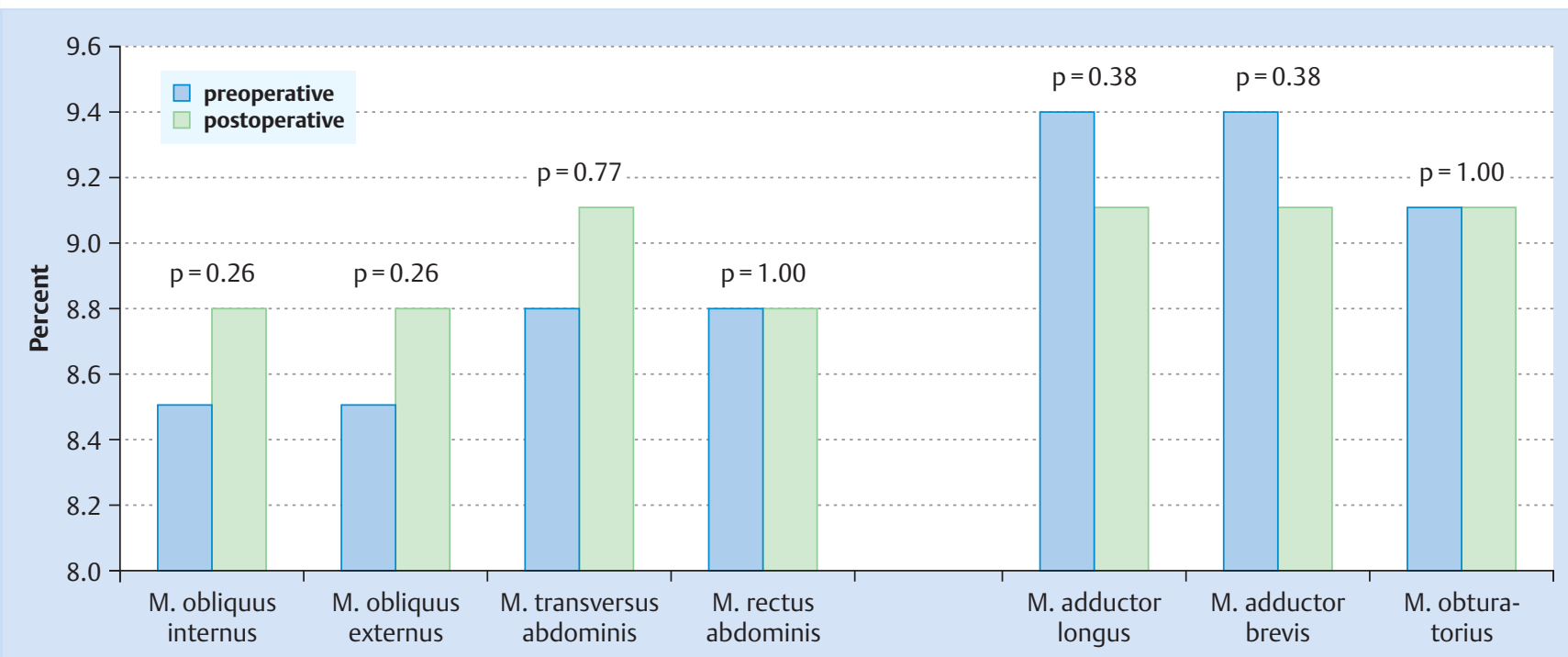

Fig. 4 Pre- and postoperative pain in patients who received a retropubic sling (postoperative means six weeks after surgery).

postoperative pain in the adductor musculature in the group with retropubic slings, but in neither of the two groups was there a statistically relevant change ( Figs. 3 and 4 ). In order to check for a possible difference due to the various techniques a case-bycase assessment was carried out for the muscles of the adductor group (M. adductor longus, M. adductor brevis) and the M. obturatorius since these muscles are most frequently mentioned as the sources of pain after placement of transobturator slings [4-6]. In both groups of patients there was one patient each with newly occurring pain and also one patient with a newly diagnosed trigger point in the adductor musculature that was not present before surgery. There were hardly any differences between the two groups with regard to pain on palpation that could not be detected prior to surgery. Also, in those patients who had received retropubic slings, new pain on palpation in the adductor muscu- lature was detected, even more frequently than in the group of patients with transobturator slings ( Table 1 ).

Table 1 Distribution of cases for the different adductor muscles (new postoperative occurrence/number of patients).

\begin{tabular}{|lll|}
\hline & Retropubic tapes & Transobturator tapes \\
\hline Pain & 1 & 1 \\
\hline Trigger points & 1 & 1 \\
\hline Pain on palpation & & \\
\hline D. M. add. longus & 5 & 4 \\
\hline - M. add. brevis & 4 & 3 \\
\hline - M. obturatorius & 6 & 5 \\
\hline
\end{tabular}




\section{Discussion}

$\nabla$

In the present study, we have focussed on the influence of suburethral slings on the abdominal and adductor muscles. Depending on the type of suburethral sling different pain patterns were expected but this could not be confirmed. Rather unexpectedly, an impact of the suburethral slings on the pelvic floor musculature was observed. This is favourably influenced by placement of a suburethral sling, irrespective of the type of sling implanted. With the registration of trigger points and pain on palpation in addition to the actively reported pain of the musculature, in the present work functional impairments of the musculature were also illustrated. Particular attention here was paid to the muscles that are perforated by the sling insertion and remain permanently within the sling material.

As a weakness of this study, e.g., the subjective reports of the investigated patients could be considered. As an alternative EMGs (electromyography) could have been taken into consideration as objective measures, however, muscle EMGs are determined as surface EMGs which are very inaccurate (possible derivation of the gluteus muscle). Needle electrode EMGs represent an invasive procedure and allow only spot conclusions. The digital pelvic floor assessment scheme according to Oxford, which is used here, is internationally established.

In the literature pain is described more frequently after placement of a transobturator sling than after placement of a retropubic sling. In the present study persisting pain or pain in the vicinity of the groin and in the region of the thigh were evaluated. Petri and Ashok described, in a study involving 338 patients with complications after sling placement, persisting pain after transobturator sling placement in $32 \%$ compared with merely $10 \%$ after placement of a retropubic sling. These, on the whole, large numbers are probably due to the particular collective of exclusively patients with complications [14]. In the available reviews pain in the vicinity of the groin and in the upper thigh region is more frequent after placement of transobturator slings (OR 8.28; 95\% CI 2.7-25.4 [4]); or significantly less after placement of retropubic slings (OR 0.32; 95\% CI 0.11-0.92; $\mathrm{p}=0.022$ [5]). Descriptions of postoperative problems with muscles, without specific details of pain, after transobturator or retropubic placement of slings only exist as isolated case reports. They concern in part massive inflammatory reactions (in the sense of fasciitis), either in the adductor musculature or in the abdominal musculature, according to the type of sling inserted $[9,10,15]$.

Upon investigation of the postoperative functionality of the musculature in dependence on the type of suburethral sling in the study described here, no statistically significant differences in the investigated parameters of the abdominal and adductor muscles occurred. Even in the case-by-case considerations of the adductor musculature that were additionally carried out in the present study because problems have been very frequently described in the literature after placement of transobturator slings, there were no differences on comparison of the two groups. However, there was only one patient in each group in whom de novo pain and trigger points were demonstrated, on the other hand there were also isolated patients in whom these symptoms were present prior to surgery but had disappeared by postoperative week six. Altogether, the results of this study do not support the notion of a specific pattern for the distribution of pain or, respectively, functional restrictions of the afflicted musculature that in general can be attributed to the type of tension-free sling or, in this relatively small study group of an increased incidence of pain incidents and functional impairments in general in the group with transobturator slings. This was a prospectively designed study of the abdominal or, respectively, adductor muscles specifically influenced by sling placement; such a study has not previously been described in the literature. Rare events such as fasciitis or myositis were not a topic of the present study.

In conclusion, both retropubic as well as transobturator slings can be used for their specific indications, can be considered equally as operative therapy for urinary incontinence, and may have similar negative impacts on the musculoskeletal systems of the abdominal and adductor muscles; only in the case of retropubic slings was this previously not specifically addressed. Pain is reported more often in the literature after transobturator slings [4-6] and the degree of distress due to pain is probably larger because it involves pain on movement. In particular, the so-called neurogenic pain should be critically assessed in the postoperative period as it usually derives from myofascial symptoms. This is also substantiated by anatomic studies that show an adequate separation of correctly placed slings from neurovascular structures [16].

A second, important result of this study is the improved strength, endurance and speed of the pelvic floor muscles after surgery, irrespective of the type of sling inserted. It is understandable that the polypropylene mesh structure strengthens the connective tissue. Rinne et al. [17] have demonstrated that the slings support the middle part of the urethra and also significantly improve the raising of the urethra by contractions of the pelvic floor muscles. The latter is also confirmed by the present work. In addition to tissue stabilisation as reason for the better contractility of the pelvic floor muscles, the satisfaction of the patients should be taken into consideration. When the patient can rely on her continence she is altogether more relaxed. This improves the relaxing ability of the entire musculature and the pelvic floor musculature in particular. In this way contractility is also increased. It can thus be assumed that postoperative pelvic floor training can be performed more effectively, that recurrences can possibly be prevented, and that the duration of success of surgical therapy can be lengthened. The efficacy of postoperative pelvic floor training was not a topic of this study. On the other hand, the present results should encourage those women who have not profited from an intensive and structured pelvic floor training to consider surgical therapy as an option in good time, since the synergistic effect of conservative and surgical therapy has been confirmed. With the confirmation that the placement of suburethral slings leads in the majority of the patients to an improved function of the pelvic floor musculature, the long known and applied treatment cascade: conservative - operative - conservative therapy has again been confirmed scientifically.

\section{Conclusions for Clinical Practice \\ $\nabla$}

In the uncomplicated postoperative courses in this study there were no significant differences in pain occurring in the abdominal and adductor muscles. The possibility of postoperative pain thus should not be a criterion in the decision as to whether a transobturator or a retropubic sling is to be implanted.

Worthy of note is the increase in strength, endurance and speed of the pelvic floor muscles after placement of a sling; this should result in the encouragement of patients to undertake or the physicians to prescribe further pelvic floor training also after surgical treatment. 


\section{Conflict of Interest}

$\nabla$

R. Tunn: Teaching activities sponsored by Gynecare (Johnson \& Johnson Medical) and AMS $^{\circledR}$.

\section{References}

1 Tunn R, Hanzal E, Perucchini D. Urogynäkologie in Praxis und Klinik. 2. Aufl. Berlin: de Gruyter; 2010: 161-181

2 Ulmsten $U$, Petros P. Intravaginal slingplasty (IVS): an ambulatory surgical procedure for treatment of female urinary incontinence. Scand J Urol Nephrol 1995; 29: 75-82

3 Nauman G, Kölbl H. Aktuelle Entwicklungen und Perspektiven in der Diagnostik und Therapie von Harninkontinenz und Genitalsenkung der Frau. Geburtsh Frauenheilk 2012; 72: 202-210

4 Latthe PM. Review of transobturator and retropubic tape procedures for stress urinary incontinence. Curr Opin Obstet Gynecol 2008; 20 : 331-336

5 Long CY, Hsu CS, Wu MP et al. Comparison of tension-free vaginal tape and transobturator tape procedure for the treatment of stress urinary incontinence. Curr Opin Obstet Gynecol 2009; 21: 342-347

6 Novara G, Artibani W, Barber MD et al. Updated systematic review and meta-analysis of the comparative data on colposuspensions, pubovaginal slings, and midurethral tapes in the surgical treatment of female stress urinary incontinence. Eur Urol 2010; 58: 218-238

7 Brubaker L, Norton PA, Albo ME et al. Adverse events over two years after retropubic or transobturator midurethral sling surgery: findings from TOMUS study. Am J Obstet Gynecol 2011; 205: 496-498
8 Enzelsberger H, Schalupny J, Heider $R$ et al. TVT versus TOT - Eine prospektiv randomisierte Studie zur operativen Behandlung der weiblichen Stressinkontinenz. Geburtsh Frauenheilk 2005; 65: 506-511

9 DeSouza R, Shapiro A, Westney OL. Adductor brevis myositis following transobturator tape procedure: a case report and review of the literature. Int Urogynecol J Pelvic Floor Dysfunct 2007; 18: 817-820

10 Lee KY, Sim JA, Lee SW et al. Necrotizing fasciitis following transobturator tape procedure: a case report and literature review. Can Urol Assoc J 2011; 5: E65-E68

11 de Leval J. Novel surgical technique for the treatment of female stress urinary incontinence: transobturator vaginal tape inside-out. Eur Urol 2003; 44: 724-730

12 Isherwood PJ, Rane A. Comparative assessment of pelvic floor strength using a perineometer and digital examination. BJOG 2000; 107: 10071011

13 Simons DG, Travell J. Myofascial trigger points, a possible explanation. Pain 1981; 10: 106-109

14 Petri E, Ashok K. Comparison of late complications of retropubic and transobturator slings in stress urinary incontinence. Int Urogynecol J 2012; 23: 321-325

15 Ogle CA, Shepherd JP, Sutkin G. Posterior rectus abdominis sheath abscess after tension-free vaginal tape. Int Urogynecol J 2012; 23: 14691471

16 Reisenauer C, Kirschniak A, Drews $U$ et al. Transobturator vaginal tape inside-out. A minimally invasive treatment of stress urinary incontinence: surgical procedure and anatomical conditions. Eur J Obstet Gynecol Reprod Biol 2006; 127: 123-129

17 Rinne K, Kainulainen S, Aukee S et al. Dynamic MRI confirms support of the mid-urethra by TVT and TVT-O surgery for stress incontinence. Acta Obstet Gynecol Scand 2011; 90: 629-635 